\title{
Pedodiversidade no estado de Minas Gerais - Brasil
}

\author{
Pedodiversity in the state of Minas Gerais - Brazil
}

Lílian Coeli Leite da Silva Geógrafa, Doutoranda em Geografia Física, UFMG liliancoeli@gmail.com

Fábio Soares de Oliveira Geógrafo, Professor do Departamento de Geografia, UFMG

fabiosolos@gmail.com

Vladimir Diniz Vieira Ramos Geógrafo, Mestre em Análise Ambiental, UFMG vladimir.diniz@,gmail.com

Carlos Ernesto Gonçalves Reynaud Schaefer Engenheiro Agrônomo, Professor do departamento de Solos, UFV carlos.schaefer@ufv.br

\section{Resumo}

A abordagem pedométrica da diversidade pedológica - ou pedodiversidade - pode ser aplicada em diversas escalas e permite identificar padrões de variabilidade espacial do sistema solo. A interpretação desses padrões evidencia características do complexo processo de formação e evolução do solo e podem subsidiar etapas do planejamento do uso e ocupação das unidades geográficas estudadas. Diversos índices para a avaliação da diversidade do objeto em análise sobre a superfície podem ser adotados em estudos de pedodiversidade. O mais comum, o índice de Shannon, foi adotado neste trabalho. Considerando as informações taxonômicas do Mapa de Solos do estado de Minas Gerais, escala 1:650.000, foi calculada a pedodiversidade para os biomas e as unidades geomorfológicas presentes no território mineiro. Ao final, foi proposto um mapa síntese da pedodiversidade em Minas Gerais. Esse mapa resulta de uma visão integradora dos resultados obtidos para os biomas e unidades geomorfológicas estudados. A depressão sanfranciscana, no contexto do bioma cerrado, caracteriza-se pela maior pedodiversidade no estado, constituindo um importante hotspot pedológico.

Palavras-chave: pedodiversidade; geografia dos solos; solos de Minas Gerais.

\begin{abstract}
Pedometric approach of soil diversity - or pedodiversity - can be applied at several scales. This approach allows identifying patterns of spatial variability of the soil system. These patterns interpretation can evidence characteristics regarding to complex soil process formation and evolution. Pedodiversity studies can subsidise too some stages of the planning of the use and occupation of the geographic units studied. Several indices for the evaluation of soil diversity can be adopted. Shannon index, selected in this work, is the most common. Considering taxonomy information from the Soil Map of the state of Minas Gerais, scale 1: 650,000, the pedodiversity was calculated for the biomes and the geomorphological units present in the territory of this state. At the end, a synthesis map to Minas Gerais pedodiversity was proposed. This map is a integrative view of results obtained for biomes and geomorphological units. The San Franciscan depression, in Cerrado biome context, is characterized by the greater pedodiversity in the state, constituting an essential pedological hotspot.
\end{abstract}

Keywords: pedodiversity; soils geography; soils of Minas Gerais. 


\section{INTRODUÇÃO}

A pedosfera apresenta inúmeras funções biogeoesféricas e se relaciona à maioria das atividades humanas desde a pré-história, apresentando relação direta com a produção de alimentos e biomassa; ao estoque, filtração e transformação de nutrientes e água; ao habitat e banco genético de milhares de seres vivos; à fonte de matéria prima para diversos grupos humanos em todo o planeta; ao estoque de carbono; e à conservação ou armazenamento de patrimônio arqueológico (CHESWORD, 2008). Porém, o reconhecimento da necessidade de preservação da pedosfera e sua integração ao patrimônio biológico, geológico e cultural é relativamente recente. A Ciência do Solo apresenta um viés agronômico histórico que justifica o predomínio de uma visão do solo como substrato para o crescimento vegetal em detrimento da sua importância ambiental. Nota-se, porém, uma mudança de foco nos estudos pedológicos e o fortalecimento da dimensão da pedosfera como parte essencial do clima e dos sistemas biogeoesféricos. Neste sentido, destacam-se estudos sobre a diversidade do solo ou pedodiversidade, os quais surgiram na Rússia durante a década de 1970 e se consolidaram a partir da década de 1990 (IBÁÑEZ; BOCKHEIM, 2013).

A origem do conceito "diversidade" liga-se aos estudos ecológicos, sendo inicialmente utilizado de forma exclusiva para os componentes bióticos da paisagem. De forma geral, a aplicação desse conceito à análise dos componentes abióticos - rochas, relevo, solos, clima - associados à dimensão cultural e econômica, compõe o que se denomina de geodiversidade (SERRANO, 2007). A caracterização da geodiversidade permite valorar, a partir de uma visão integrada, recursos naturais que compõem a arquitetura das paisagens, considerando sua complexidade em variadas escalas espaciais (IBAÑEZ et al., 1995). O conceito de pedodiversidade insere-se neste contexto e compõe, portanto, apenas uma das dimensões do abrangente conceito de geodiversidade.

A análise da pedodiversidade pode ser realizada a partir de informações de campo, levantamentos digitalizados ou bases de dados pedológicos (IBÁÑEZ; BOCKHEIM, 2013). Neste sentido, os mapas pedológicos apresentam corpos de solos admitidamente artificiais, os quais resultam do processo de sumarização e representação da complexa realidade do solo na paisagem. Embora os mapas de solo apresentem unidades heterogêneas decorrentes de inclusões e variações; uma certa imprecisão dos limites delineados; e ausência de importantes informações de subsuperfície (HOLE, 1978) é inegável a importância e validade dessas informações.

A geografia dos solos ou geopedologia está pautada no entendimento da evolução e inserção dos solos nas diversas paisagens que compõem o globo. Trata-se de uma importante perspectiva de estudo considerando que uma interpretação acurada do solo pressupõe a análise do seu codesenvolvimento com a paisagem ao longo do tempo, em variadas escalas espaciais e temporais (SCHAETZL; ANDERSON, 2005). Padrões observados em determinadas escalas normalmente não 
estão presentes em outras. Logo, altos níveis de generalização associados a escalas de análise regional podem evidenciar determinados padrões espaciais ausentes em mapas de alta resolução, comumente utilizados em escalas locais (MILLER; SCHAETZL, 2016). O conhecimento geográfico do solo e o seu avanço também decorrem das análises de variabilidade espacial nos mapas pedológicos em suas múltiplas escalas, as quais devem ser consideradas em suas especificidades e potencialidades.

Estudos de pedodiversidade de cunho pedométrico apresentam uma natureza taxonômica ou funcional. A avaliação da pedodiversidade ligada à taxonomia considera os grupos de solos presentes em mapas com escala regional ou classes individuais em mapas com escala local. Já a análise da pedodiversidade com natureza funcional é pautada na heterogeneidade dos parâmetros do solo. Ambas se destacam pela sua potencialidade em avaliar a variabilidade espacial dos solos e podem ser associadas a várias unidades geográficas para o cálculo da pedodiversidade. Dentre essas unidades, destacam-se limites políticos, áreas determinadas para estudos ambientais com finalidades diversas, bacias hidrográficas e zonas bioclimáticas (ALYABINA, 2018).

Para estudos de avaliação taxonômica, conforme Ibañez et al. (1998), é importante realizar uma análise que prioriza principalmente as semelhanças entre as diversas classes em detrimento das diferenças. Neste sentido, destaca-se a avaliação da pedodiversidade a partir das grandes unidades de mapeamento com associações às classes de solos que recobrem essas extensas áreas. Tal avaliação é realizada a partir da identificação dos diferentes tipos de solos, e sua classificação ocorre a partir de uma concepção morfo-genética, diretamente associada às propriedades e atributos que se expressam na escala macroscópica. A pedodiversidade associa-se a fatores extrínsecos ou intrínsecos ao sistema solo, embora muitas vezes esses dois tipos de fatores sejam dificilmente diferenciáveis considerando que os solos apresentam uma complexidade genética e evolutiva resultante de um longo processo de formação. A análise espacial das diversas classes de solo a partir dessas grandes unidades de mapeamento podem evidenciar determinados padrões no processo de formação e evolução pedológica que permitem planejar de forma racional o uso e ocupação das unidades geográficas estudadas a partir de suas especificidades (PHILLIPS, 2001b).

Tais ideias se aplicam à análise do mosaico pedológico inserido em Minas Gerais. O território do estado - cuja área é de aproximadamente 58.651.900 ha (IBGE, 2015) - se caracteriza pela ocorrência das 13 classes que constituem o Sistema Brasileiro de Classificação de Solos (SiBCS) (SANTOS et al., 2018). Tal mosaico pedológico resulta da atuação de climas variados, ao longo do tempo, sobre um substrato geológico diverso, que, por sua vez, constitui o arcabouço de unidades geomorfológicas e biogeográficas variadas, as quais apresentam co-desenvolvimento ao sistema solo.

Face ao exposto, esse estudo apresenta um estudo taxonômico da pedodiversidade em Minas Gerais a partir das associações de solos apresentadas nas quatro folhas que compõem o Mapa de Solos do estado de Minas Gerais, escala 1:650:000, elaborado pela FEAM et al., (2010). De forma geral, 
esse estudo enfatiza a importância de considerar o potencial das avaliações de pedodiversidade como reveladores da riqueza dos solos presentes numa área, e como ela interage com distintos fatores geoambientais a fim se melhor compreender as variações espaciais do solo no território mineiro. Especificamente, destacam-se três abordagens: a primeira constitui uma avaliação taxonômica da pedodiversidade a partir dos biomas presentes no estado de Minas Gerais; a segunda, uma avaliação taxonômica da pedodiversidade considerando as unidades geomorfológicas no estado conforme proposto pelo CETEC (1982); e por fim, uma avaliação taxonômica da pedodiversidade que conjuga os biomas e as unidades geomorfológicas realizada a partir de álgebra de mapas.

\section{PROCEDIMENTOS METODOLÓGICOS}

Os procedimentos envolveram a busca por demonstrar a diversidade de classes de solos em Minas Gerais na escala regional. A análise da variação da distribuição espacial dos solos pode ser realizada a partir de uma concepção pedogeomorfológica (HUDSON, 1992) ou pedométrica (IBAÑEZ et al., 1998; PHILLIPS 2001a; GUO et al., 2003; MCBRATNEY; MINASNY, 2007; SALDAÑA; IBAÑEZ, 2007). No segundo caso, é comum que os estudos apresentem a análise da frequência de cada classe de solo no âmbito da área analisada, dentro da qual se utiliza toda a área ou compartimentações feitas nessas. Além disso, são utilizados diversos índices que mensuram a diversidade de um fenômeno/objeto sobre a superfície. O índice mais comum em estudos de pedodiversidade é o índice de Shannon, expresso pela fórmula:

$$
H^{\prime}=-\Sigma p i \ln p i
$$

onde, pi é calculado pela relação entre ni/N, na qual ni é a área coberta por uma dada categoria de solo e $\mathrm{N}$ a área total estudada. O H' consiste em um índice de riqueza no qual são considerados um número de categorias que ocorrem em uma área de amostragem definida (IBAÑEZ et al., 1998).

Além do índice de Shannon, relacionado ao conceito de riqueza, destaca-se o índice de medida de regularidade ou índice de Pielou, representado pela fórmula:

$$
E=H^{\prime} H \max =H^{\prime} / \ln S
$$

onde, S é o número de categorias de solo. O valor de E encontra-se no intervalo de $|0,1|$ e representa a abundância proporcional das categorias. Não apenas o número, mas também a sua relativa abundância - no caso, a área ocupada por cada ordem e subordem de solo considerada (IBAÑEZ et al., 1998).

Jenny (1941) define o solo como o resultado da interação entre o clima, organismos vivos, relevo e material de origem. Bockheim et al. (2005) destacam o clima como um fator de condução da pedogênese na escala continental; organismos como um fator chave, desde a escala microscópica até 
a escala continental; material de origem com um papel de destaque na escala regional; e o relevo, especificamente a topografia, com forte condicionamento na paisagem.

O entendimento da variação e distribuição espacial dos solos pressupõe, portanto, uma visão conjunta entre os elementos físicos e bióticos que compõem as paisagens. Neste sentido, optou-se por realizar uma primeira avaliação da pedodiversidade a partir da compartimentação de unidades geoecológicas, especificamente os biomas, os quais podem ser utilizados como referência espacial importante para a análise da variação de solos. Uma segunda avaliação foi realizada considerando os limites das unidades geomorfológicas propostas no mapeamento realizado pelo CETEC (1982). Posteriormente, foi realizada uma análise integrada entre os biomas e as unidades geomorfológicas. Os resultados dessa análise foram espacializados e constitui o mapa da pedodiversidade para o estado de Minas conforme os elementos de análise selecionados nesse trabalho. Logo, a análise da diversidade pedológica em Minas Gerais é apresentada considerando: i) a área ocupada por cada classe no estado como um todo; ii) as classes de solos, sua frequência e diversidade nos biomas que ocorrem em Minas Gerais (IBGE, 2004); iii) as unidades geomorfológicas (CETEC, 1982) e valores associados; e iv) a avaliação taxonômica final pautada em aspectos geomorfológicos e geoecológicos do território mineiro.

Para o cálculo dos índices Shannon e Pielou, respectivamente nos biomas e unidades geomorfológicas (CETEC, 1982), foram utilizados os dados apresentados nas 
Tabela 1 e 2. As áreas ocupadas pelas classes de solos associadas a cada um dos biomas (Tab. 1) é uma composição das ordens e subordens das associações de mapeamento apresentadas pela FEAM et al., (2010), tendo como referência os limites propostos por IBGE (2004) para a caatinga, cerrado e mata atlântica em Minas Gerais. Para o cálculo das áreas ocupadas pelas ordens e subordens de solo (FEAM et al., 2010) em relação às unidades geomorfológicas do mapeamento foram utilizadas as ferramentas do software ArcGIS 10.1 clip e calculate area.

Por fim, foram utilizados recursos de álgebra de mapas e cartografia digital nesse mesmo software para a elaboração do mapa final referente à Pedodiversidade em Minas Gerais. O mapa síntese foi elaborado a partir da soma simples dos valores de pedodiversidade - índice de Shannon obtidos para os biomas e para as unidades geomorfológicas. Os valores foram convertidos em uma escala qualitativa e apresentados no contexto do território de Minas Gerais. 
Tabela 1 - Área (\%) ocupada pelas ordens e subordens de solo (FEAM et al., 2010) nos biomas Caatinga, Cerrado e Mata Atlântica.

\begin{tabular}{lccc}
\hline & Caatinga & Cerrado & Mata Atlântica \\
\hline & & & 9,88897 \\
ARGISSOLO VERMELHO & 0,00000 & 0,19283 & 11,59240 \\
ARGISSOLO VERMELHO - AMARELO & 2,32651 & 5,32586 & 0,16643 \\
CAMBISSOLO FLÚVICO & 0,00000 & 0,00000 & 12,50005 \\
CAMBISSOLO HÁPLICO & 10,98768 & 21,08721 & 0,95867 \\
CAMBISSOLO HÚMICO & 0,00000 & 0,00000 & 0,00000 \\
GLEISSOLO HÁPLICO & 0,00000 & 0,17281 & 0,05958 \\
GLEISSOLO MELÂNICO & 0,00000 & 0,45675 & 2,87769 \\
LATOSSOLO AMARELO & 0,00000 & 0,54242 & 15,08945 \\
LATOSSOLO VERMELHO & 10,65237 & 30,09020 & 43,60625 \\
LATOSSOLO VERMELHO - AMARELO & 60,31273 & 18,99928 & 0,12931 \\
LUVISSOLO CRÔMICO & 0,00000 & 0,00000 & 0,09050 \\
NEOSSOLO FLÚVICO & 14,12934 & 2,69355 & 2,37956 \\
NEOSSOLO LITÓLICO & 0,52027 & 14,39076 & 0,00543 \\
NEOSSOLO QUARTZARÊNICO & 0,39019 & 4,80841 & 0,23900 \\
NITOSSOLO HÁPLICO & 0,14167 & 0,74556 & 0,41672 \\
NITOSSOLO VERMELHO & 0,12807 & 0,32028 & 0,00000 \\
PLANOSSOLO HÁPLICO & 0,41117 & 0,00160 & 0,00000 \\
PLINTOSSOLO ARGILÚVICO & 0,00000 & 0,17248 & $24.203 .831,51350$ \\
Área Total (ha) & & & $33.379 .593,80620$ \\
\hline
\end{tabular}


Tabela 2 - Área (\%) ocupada pelas ordens e subordens de solo (FEAM et al., 2010) por Unidade Geomorfológica (CETEC, 1982).

\begin{tabular}{|c|c|c|c|c|c|c|c|c|c|c|c|c|c|c|c|c|c|c|}
\hline & (1) & (2) & (3) & (4) & (5) & (6) & (7) & (8) & (9) & (10) & (11) & (12) & (13) & (14) & (15) & (16) & (17) & (18) \\
\hline $\begin{array}{l}\text { ARGISSOLO } \\
\text { VERMELHO }\end{array}$ & 0,00000 & 45,69992 & 10,52873 & 0,00000 & 0,00000 & 1,61423 & 22,32245 & 0,00000 & 0,32219 & 13,47337 & 0,00000 & 0,00000 & 4,83425 & 5,38686 & 2,42868 & 18,89604 & 0,08236 & 0,00000 \\
\hline $\begin{array}{l}\text { ARGISSOLO } \\
\text { VFRMFI HO }\end{array}$ & & & & & & & & & & & & & & & & & & 163688 \\
\hline $\begin{array}{l}\text { VERMELHO - } \\
\text { AMARELO }\end{array}$ & 0,00000 & 7,10495 & 8,34421 & 50,45496 & 4,14636 & 13,76927 & 3,54273 & 6,56796 & 4,86646 & 14,72884 & 11,92096 & 3,16061 & 11,75997 & 0,04515 & 5,53419 & 7,72899 & 2,74357 & 1,63688 \\
\hline $\begin{array}{l}\text { CAMBISSOLO } \\
\text { FLÚVICO }\end{array}$ & 0,00000 & 2,32483 & 0,00000 & 0,00000 & 0,00000 & 0,00000 & 0,00000 & 0,00000 & 0,00000 & 0,00000 & 0,00000 & 0,00000 & 0,04886 & 0,00000 & 0,00000 & 0,00000 & 0,00000 & 0,00000 \\
\hline $\begin{array}{l}\text { CAMBISSOLO } \\
\text { HÁPLICO }\end{array}$ & 13,55706 & 15,71461 & 12,86206 & 1,35137 & 21,51956 & 4,38534 & 7,42988 & 22,77839 & 2,96319 & 10,91233 & 36,87319 & 17,76561 & 10,57825 & 38,48464 & 47,63180 & 24,64235 & 14,45102 & 0,00000 \\
\hline $\begin{array}{l}\text { CAMBISSOLO } \\
\text { HÚMICO }\end{array}$ & 0,00000 & 0,00000 & 0,01069 & 0,00000 & 0,00000 & 0,01039 & 0,00000 & 0,00000 & 0,00000 & 3,26724 & 0,00000 & 0,00000 & 0,40213 & 0,00000 & 0,00000 & 12,47644 & 0,00000 & 0,00000 \\
\hline $\begin{array}{l}\text { GLEISSOLO } \\
\text { HÁPLICO }\end{array}$ & 0,00722 & 0,00000 & 0,00000 & 0,00000 & 0,00000 & 0,00000 & 0,00000 & 0,39401 & 0,00000 & 0,00000 & 0,00000 & 0,19898 & 0,00000 & 0,00000 & 0,00000 & 0,00000 & 0,00000 & 0,00000 \\
\hline $\begin{array}{l}\text { GLEISSOLO } \\
\text { MELÂNICO }\end{array}$ & 0,00000 & 0,00000 & 0,63669 & 0,00000 & 0,00000 & 0,00000 & 0,00000 & 0,02436 & 1,44006 & 0,06096 & 0,00000 & 0,54596 & 0,08150 & 0,00000 & 0,00000 & 0,00000 & 0,00000 & 0,00000 \\
\hline $\begin{array}{l}\text { LATOSSOLO } \\
\text { AMARELO }\end{array}$ & 0,00000 & 7,68442 & 0,43441 & 0,20326 & 0,00000 & 12,22988 & 0,00000 & 1,01019 & 0,00000 & 0,00000 & 7,20397 & 0,00000 & 1,48703 & 0,00000 & 0,00000 & 1,68187 & 0,00000 & 0,00000 \\
\hline $\begin{array}{l}\text { LATOSSOLO } \\
\text { VERMELHO }\end{array}$ & 7,46306 & 1,52814 & 44,86618 & 4,48764 & 66,17838 & 2,21709 & 66,70494 & 23,03714 & 84,09737 & 22,14939 & 16,58201 & 7,27202 & 9,85519 & 7,72131 & 13,97545 & 1,28109 & 19,39269 & 0,00000 \\
\hline LATO & & & & & & & & & & & & & & & & & & \\
\hline $\begin{array}{l}\text { VERMELHO - } \\
\text { AMARELO }\end{array}$ & 2,57198 & 19,43523 & 16,56100 & 27,28153 & 0,00123 & 65,63556 & 0,00000 & 22,60779 & 2,92963 & 33,25668 & 23,18061 & 38,35365 & 59,58620 & 13,25717 & 4,67389 & 30,30904 & 5,18471 & 98,36312 \\
\hline $\begin{array}{l}\text { LUVISSOLO } \\
\text { CRÔMICO }\end{array}$ & 0,00000 & 0,00000 & 0,00000 & 5,19111 & 0,00000 & 0,00000 & 0,00000 & 0,00000 & 0,00000 & 0,00000 & 0,00000 & 0,00000 & 0,00587 & 0,00000 & 0,00000 & 0,00000 & 0,00000 & 0,00000 \\
\hline $\begin{array}{l}\text { NEOSSOLO } \\
\text { FLÚVICO }\end{array}$ & 2,32634 & 0,00000 & 0,60684 & 0,00000 & 0,05653 & 0,00000 & 0,00000 & 8,19806 & 0,01852 & 0,19617 & 0,63709 & 1,09382 & 0,00000 & 0,00000 & 0,00000 & 0,00000 & 0,04456 & 0,00000 \\
\hline $\begin{array}{l}\text { NEOSSOLO } \\
\text { LITÓLICO }\end{array}$ & 74,07434 & 0,50790 & 3,89453 & 0,00000 & 8,09794 & 0,13824 & 0,00000 & 8,74489 & 2,71214 & 1,19571 & 1,95670 & 23,28199 & 1,25556 & 35,10487 & 18,89534 & 2,98419 & 54,07620 & 0,00000 \\
\hline $\begin{array}{c}\text { NEOSSOLO } \\
\text { QUARTZARÊNICO }\end{array}$ & 0,00000 & 0,00000 & 0,00000 & 0,00000 & 0,00000 & 0,00000 & 0,00000 & 4,93633 & 0,56517 & 0,00000 & 0,00000 & 6,70391 & 0,00000 & 0,00000 & 0,00000 & 0,00000 & 3,59284 & 0,00000 \\
\hline $\begin{array}{l}\text { NITOSSOLO } \\
\text { HÁPLICO }\end{array}$ & 0,00000 & 0,00000 & 0,79708 & 0,00000 & 0,00000 & 0,00000 & 0,00000 & 1,20485 & 0,00000 & 0,75932 & 0,00000 & 1,59355 & 0,09712 & 0,00000 & 0,00000 & 0,00000 & 0,00000 & 0,00000 \\
\hline $\begin{array}{l}\text { NITOSSOLO } \\
\text { VERMELHO }\end{array}$ & 0,00000 & 0,00000 & 0,25485 & 11,03012 & 0,00000 & 0,00000 & 0,00000 & 0,37853 & 0,08527 & 0,00000 & 1,64547 & 0,02990 & 0,00806 & 0,00000 & 0,05029 & 0,00000 & 0,43206 & 0,00000 \\
\hline $\begin{array}{l}\text { PLANOSSOLO } \\
\text { HÁPLICO }\end{array}$ & 0,00000 & 0,00000 & 0,00000 & 0,00000 & 0,00000 & 0,00000 & 0,00000 & 0,04566 & 0,00000 & 0,00000 & 0,00000 & 0,00000 & 0,00000 & 0,00000 & 0,00000 & 0,00000 & 0,00000 & 0,00000 \\
\hline $\begin{array}{l}\text { PLINTOSSOLO } \\
\text { ARGILÚVICO }\end{array}$ & 0,00000 & 0,00000 & 0,20272 & 0,00000 & 0,00000 & 0,00000 & 0,00000 & 0,07183 & 0,00000 & 0,00000 & 0,00000 & 0,00000 & 0,00000 & 0,00000 & 6,81037 & 0,00000 & 0,00000 & 0,00000 \\
\hline $\begin{array}{l}\text { Área Total (ha) } \\
\text { Unidade } \\
\text { Geomorfológica } \\
\text { CETEC, 1982) }\end{array}$ & 294830 & 1659570 & 2401140 & 689508 & 994900 & 1787640 & 63261,6 & 11.203 .600 & 5802040 & 1773100 & 5965700 & 10064700 & 10674400 & 493514 & 798429 & 1179010 & 1502180 & 680813 \\
\hline
\end{tabular}

(1) Cristas de Unaí; (2) Depressão do Rio Doce; (3) Depressão do Rio Grande; (4) Depressão do Rio Jequitinhonha; (5) Depressão do Rio Paranaíba; (6) Depressão do Rio Paraíba do Sul; (7) Depressão Periférica Paulista;

(8) Depressão Sanfranciscana; (9) Planalto da Bacia do Paraná; (10) Planalto Dissecado do Sul de Minas; (11) Planalto do Rio Jequitinhonha - Rio Pardo; (12) Planalto do São Francisco; (13) Planaltos Dissecados do

Centro - Sul e do Leste de Minas; (14) Quadrilátero Ferrífero; (15) Serra da Canastra; (16) Serra da Mantiqueira; (17) Serra do Espinhaço; (18) Zona Rebaixada do Rio Mucuri. 


\section{RESULTADOS E DISCUSSÃO}

\subsection{Distribuição geral das classes de solos em minas gerais}

Sob o ponto de vista pedológico, Minas Gerais é um território constituído por solos ácidos e pobres quimicamente. No estado predominam, respectivamente, Latossolos Vermelho - Amarelos, Latossolos Vermelhos, Cambissolos Háplicos e Neossolos Litólicos. Considerando a área ocupada por cada classe, os Latossolos abrangem, aproximadamente, 53,50\% do território mineiro (Fig. 1). Tratam-se de coberturas estáveis, essencialmente caulinito-gibbsíticas (AMORIM FILHO; BUENO, 2002), em avançado estágio de intemperismo, cuja evolução resulta de transformações intensas no material de origem. São solos profundos, com boas condições de drenagem, baixa capacidade de troca catiônica (CTC), quase sempre ácidos. Originam-se de material de origem diversos e tendem a se localizar, sobretudo, em amplas e antigas superfícies de erosão, pedimentos ou terraços fluviais antigos (SANTOS et al., 2018).

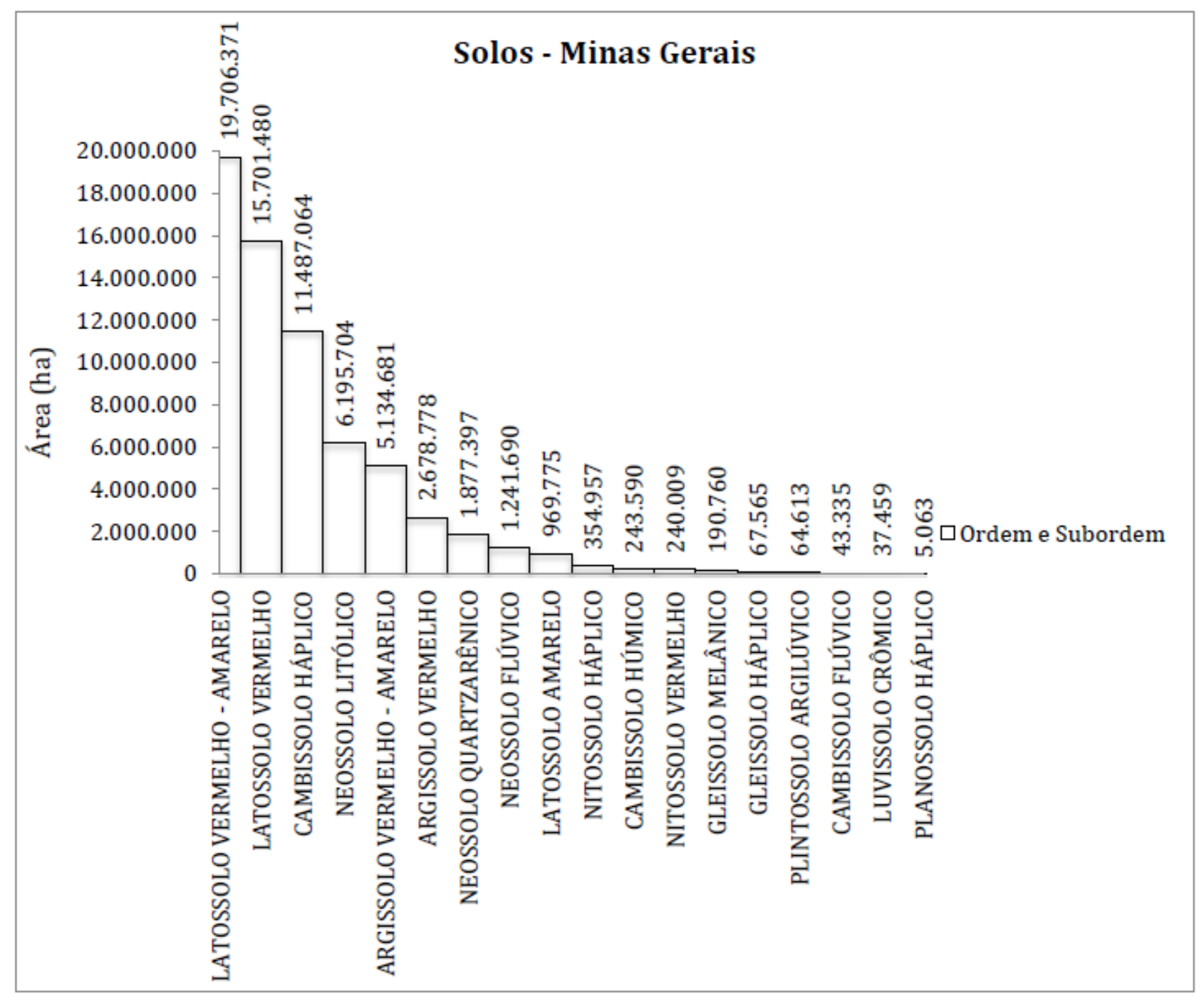

Figura 1 - Área (ha) ocupada pelas principais classes de solo (FEAM et al., 2010) em Minas Gerais. 
Em termos de área de ocorrência, após os Latossolos, destacam-se os Cambissolos, associados a aproximadamente $18 \%$ do estado. O prefixo "cambi" deriva do latim cambiare, que significa mudar, transformar. Os Cambissolos constituem, portanto, solos em transformação (SANTOS et al., 2018). Os horizontes B incipientes pertencentes aos Cambissolos são relativamente jovens, muito relacionados ao material de origem ou a horizontes diagnósticos previamente existente e que, por processos morfogenéticos, foram erodidos.

Os Argissolos ocupam aproximadamente 12\% de Minas Gerais. Caracterizam-se por um aumento no teor de argila do horizonte A para o horizonte B. O horizonte B textural é o horizonte diagnóstico associado ao processo de acumulação de argila, vertical ou lateral, ou perda de argila dos horizontes superiores. Os Neossolos ocupam aproximadamente 11\% da área total do estado. Essa classe se caracteriza por solos pouco espessos, sem alterações expressivas em relação ao material de origem devido à resistência do material de origem ou associado a outros fatores de formação do solo que podem limitar a atuação da pedogênese (SANTOS et al., 2018).

Apesar de ocorrerem no estado de Minas, as classes dos Chernossolos, Espodossolos, Vertissolos e Organossolos não ocorrem em escala compatível às unidades de mapeamento do projeto Mapa de Solos do Estado de Minas Gerais. Áreas mapeadas que não correspondem a classes de solos - água e afloramento - constituem 3,52\% do território mineiro.

\subsection{A pedodiversidade nos biomas}

A arranjo geoecológico de Minas Gerais resulta do cruzamento de três biomas, em um contexto de mescla. Isso significa que o território mineiro - considerando a ótica de Ab'Saber (2003) e a teoria dos domínios morfoclimáticos - configura uma faixa de transição ambiental, cujos limites na realidade não são abruptos quanto os propostos pelo IBGE (2004) para os biomas. A transição entre um e outro é gradual, na qual elementos de outros biomas encontram-se imiscuídos, especialmente no Cerrado, que se caracteriza, a priori, por ser um bioma de contato.

A organização das atividades econômicas e o modo de vida em Minas Gerais está associada aos três grandes domínios. O bioma Cerrado caracteriza-se por grupos humanos que habitam as chapadas e apresentam tradicionalmente uma forte relação com o extrativismo e a criação de gado. Atualmente, esse uso tradicional nas chapadas entra em conflito com a fronteira agrícola em expansão relacionada ao agronegócio das commodities que avança sobre o cerrado em todo o país (MAZZETTO SILVA, 2009). A Mata Atlântica mineira, em um contexto ambiental montano mais afastado da influência marítima, é habitada por grupos humanos cujas práticas econômicas vinculamse tradicionalmente ao cultivo de café, banana, milho, feijão e à exploração mineral. Na caatinga, 
caracteriza pela aridez, os vazanteiros, quilombolas e geraizeiros constituem grupos humanos cujo modo de vida é marcado pelo isolamento e resistência.

As características relacionadas a cada um dos biomas encontram-se generalizadas nas Tabelas 3, 4 e 5, considerando não só a escala adotada, mas também a própria complexidade geoecológica de Minas Gerais, brevemente descrita.

No Cerrado há o predomínio da classe dos Latossolos Vermelhos (Tab. 3). Tal classe ocupa aproximadamente $26 \%$ da área, especificamente na região do Triângulo Mineiro, na qual o relevo aplainado associado às coberturas sedimentares da bacia do Paraná, às altas temperaturas e ao regime pluviométrico do clima Tropical Quente Úmido e Semiúmido favorecem a ocorrência do processo de latossolização. Na porção noroeste do bioma cerrado em Minas Gerais, ocorrem Latossolos Vermelho - Amarelos entremeados a Latossolos Vermelhos, Neossolos Quartzarênicos, Neossolos Flúvicos e Cambissolos Háplicos. As manchas de Neossolos Quartzarênicos associam-se aos arenitos e os Neossolos Flúvicos aos sedimentos do Rio São Francisco e afluentes. Na porção centro-oeste, destaca-se uma mancha de Cambissolo Háplico associado à Serra da Canastra, e as manchas de Neossolo Litólico associam-se às rochas de maior resistência ao intemperismo, como os quartzitos da Serra do Espinhaço e Serra do Cabral.

Diferente do bioma cerrado, na Mata Atlântica preponderam os Latossolos Vermelho Amarelos, seguidos pelos Latossolos Vermelhos e Argissolos (Tab.4). As manchas de Latossolos encontram-se associadas às manchas de Argissolos, constituindo um sistema de transformação Latossolos - Argissolos no contexto dos mares de morros.

$\mathrm{Na}$ área do bioma caatinga inserido no território mineiro, predomina a classe dos Latossolos Vermelho - Amarelos (Tab. 5). Considerando as condições climáticas e a vegetação associada a este domínio, tais solos predominantes associam-se a paleoclimas mais úmidos que permitiram a ocorrência da latossolização em um ambiente que atualmente caracteriza-se pelo déficit hídrico (Schaefer, 2013).

Comparativamente, os biomas Cerrado e Mata Atlântica apresentam 15 tipos de solos, considerando a riqueza em termos de ordem e subordem. Para a Caatinga, foram registrados 10 tipos de solos (Tab. 5). Ibañez et al. (1998) atentam que os valores de riqueza tendem a apresentar maiores diferenças em áreas com diferentes tipos climáticos. Tal diferença é evidente para a Caatinga, a qual apresenta características climáticas mais marcantes e peculiares quando comparada ao Cerrado e à Mata Atlântica e um menor valor de riqueza no que se refere à ordem e subordem. 
Tabela 3 - Bioma Cerrado.

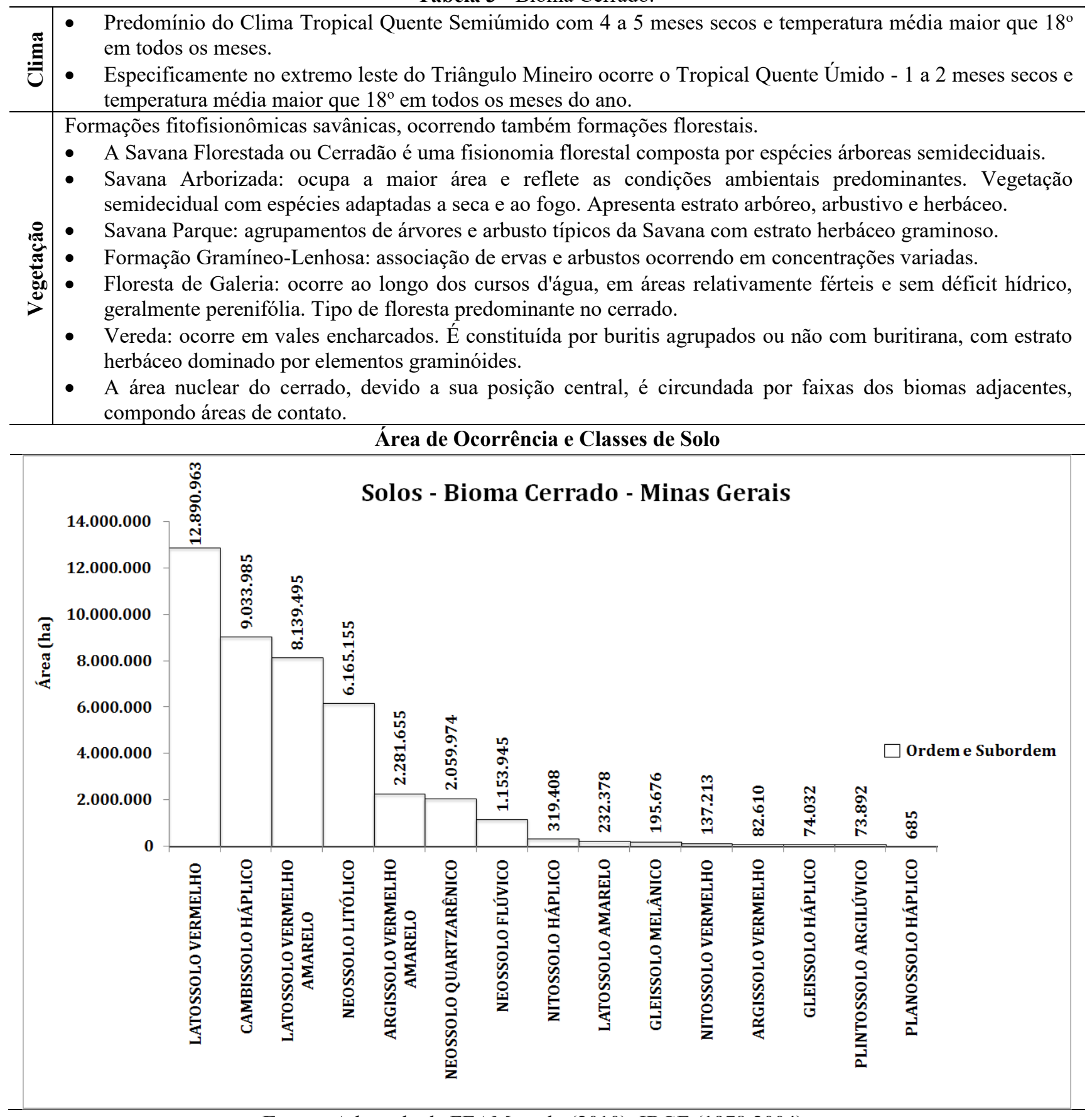

Fonte - Adaptado de FEAM et al., (2010); IBGE (1978;2004). 
Tabela 4 - Bioma Mata Atlântica.

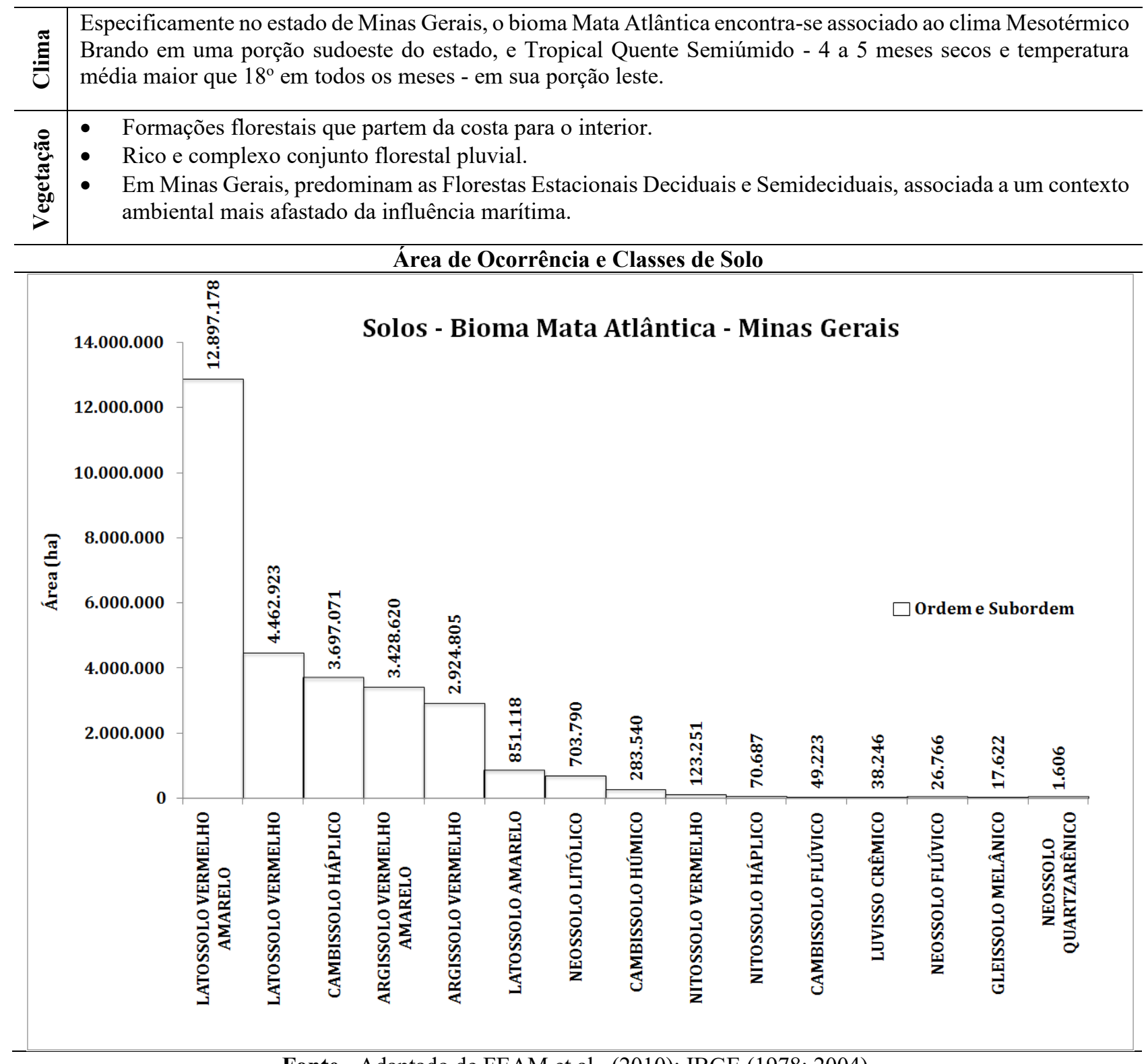

Fonte - Adaptado de FEAM et al., (2010); IBGE (1978; 2004).

Dentre os três biomas que ocorrem no estado de Minas Gerais, o Cerrado apresenta a maior pedodiversidade, considerando o valor de 1,82 do índice de Shannon (Fig. 2). Esse bioma apresenta também maior valor de abundância relativa ou área ocupada $(\mathrm{E}=0,67)$ pela ordem e subordens consideradas. O maior valor de E para o Cerrado associa-se a sua maior área no estado quando comparada à Mata Atlântica, considerando que ambos os biomas possuem os mesmos valores de $\mathrm{H}_{\max }$ por apresentarem os mesmos valores de riqueza em termos de ordem e subordem. 
Tabela 5 - Bioma Caatinga.

\begin{tabular}{|c|c|}
\hline 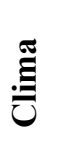 & $\begin{array}{l}\text { - Clima Quente Semi-Árido - com } 6 \text { meses secos e temperatura média maior que } 18^{\circ} \text { em todos os meses. Ocorrência } \\
\text { de dois períodos secos anuais. } \\
\text { - Um longo déficit hídrico seguidos por chuvas intermitentes, e outro com período curto de seca seguido de chuvas } \\
\text { torrenciais. }\end{array}$ \\
\hline 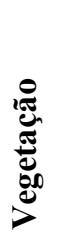 & $\begin{array}{l}\text { - A Savana Estépica ou Caatinga é caracterizada por uma fisionomia decidual e espinhosa. } \\
\text { - As estações de chuva e seca acentuam os contrastes fisionômicos. } \\
\text { - } \quad \text { Durante o período seco, a caatinga apresenta-se despida, cinzenta e espinhosa. Durante a estação chuvosa, a } \\
\text { vegetação se adensa com ervas e ramificação dos arbustos e árvores. } \\
\text { - Áreas minoritárias, com bolsões climáticos mais amenos, tais como brejos e áreas serranas, abrigam florestas } \\
\text { deciduais e semideciduais. }\end{array}$ \\
\hline
\end{tabular}

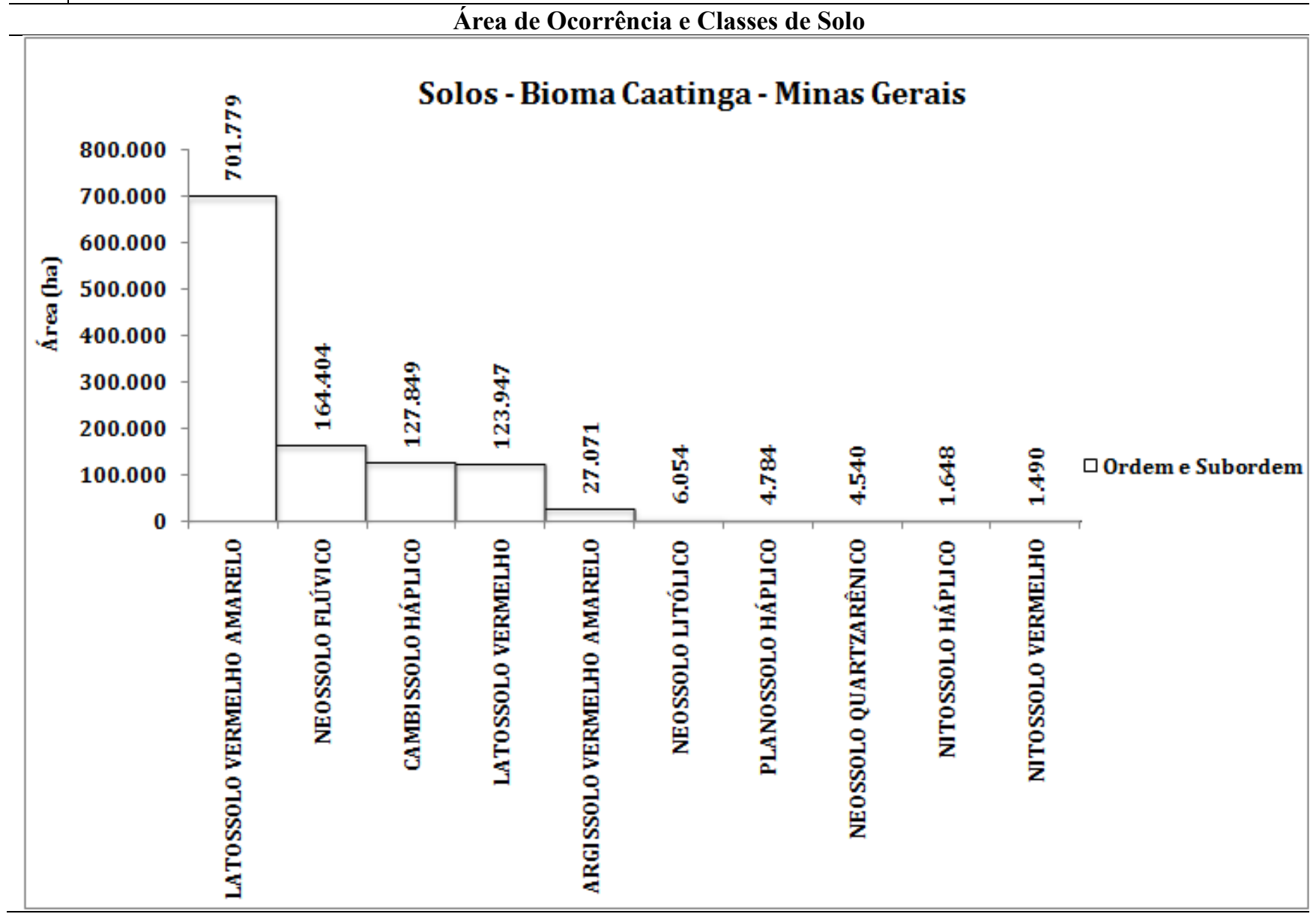

Fonte - Adaptado de FEAM et al., (2010); IBGE (1978;2004).

A máxima pedodiversidade do Cerrado encontra-se associada à própria complexidade da estrutura das paisagens desse bioma, constituída por inúmeras fitofisionomias em um contexto de ecótono. O sistema solo, como importante elemento estratificador da paisagem, é a própria síntese dessa complexidade ao se apresentar com a maior variedade taxonômica nesse bioma em Minas Gerais. 


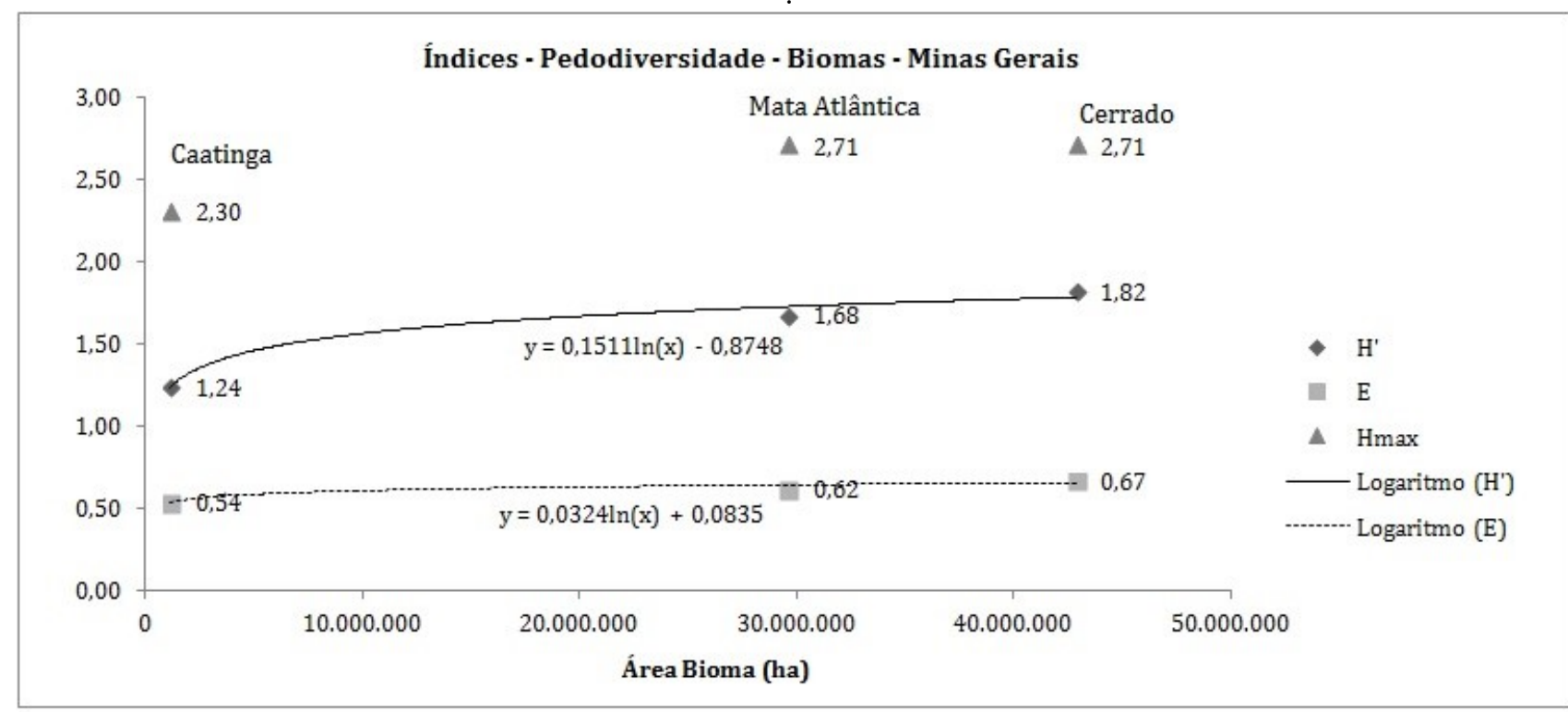

Figura 2 - Riqueza (ordem e subordem), índices de diversidade (H', Hmax) e regularidade (E) das classes de solos (FEAM et al., 2010) em relação aos biomas no estado de Minas Gerais

\subsection{Pedodiversidade e as unidades geomorfológicas em Minas Gerais}

Os resultados para os índices de pedodiversidade calculados para as unidades geomorfológicas (CETEC, 1982) são apresentados na Tab.6 e Fig. 3. Em termos de riqueza, destacam-se as unidades geomorfológicas: Depressão Sanfranciscana, Planaltos Dissecados do Centro-Sul e do Leste de Minas e Depressão do Rio Grande, os quais apresentam respectivamente 14, 13 e 13 tipos de solos em suas áreas. A Zona Rebaixada do Rio Mucuri possui apenas dois tipos de solos em sua área, caracterizando-se por apresentar a menor riqueza.

Tabela 6 - Riqueza (ordem e subordem), índices de diversidade (H', Hmax) e regularidade (E) das classes de solos (FEAM et al., 2010) em relação às Unidades Geomorfológicas (CETEC, 1982) no estado de Minas Gerais.

\begin{tabular}{|c|c|c|c|c|c|}
\hline Unidade & $\begin{array}{c}\text { Área Considerada } \\
\text { (ha) }\end{array}$ & $\begin{array}{c}\text { Riqueza } \\
\text { (ordem e subordem) }\end{array}$ & $\mathbf{H}^{\prime}$ & Hmax & $\mathbf{E}$ \\
\hline Cristas de Unaí & $294.830,00$ & 6,00 & 0,87 & 1,79 & 0,49 \\
\hline Depressão do Rio Doce & $1.659 .570,00$ & 8,00 & 1,53 & 2,08 & 0,74 \\
\hline Depressão do Rio Grande & $2.401 .140,00$ & 13,00 & 1,65 & 2,56 & 0,64 \\
\hline Depressão do Rio Jequitinhonha & $689.508,00$ & 7,00 & 1,30 & 1,95 & 0,67 \\
\hline Depressão do Rio Paraíba do Sul & $994.900,00$ & 8,00 & 1,10 & 2,08 & 0,53 \\
\hline Depressão do Rio Paranaíba & $1.787 .640,00$ & 6,00 & 0,94 & 1,79 & 0,53 \\
\hline Depressão Periférica Paulista & $63.261,60$ & 4,00 & 0,92 & 1,39 & 0,66 \\
\hline Depressão Sanfranciscana & $11.203 .600,00$ & 14,00 & 1,91 & 2,64 & 0,72 \\
\hline Planalto da Bacia do Paraná & $5.802 .040,00$ & 10,00 & 0,71 & 2,30 & 0,31 \\
\hline Planalto Dissecado do Sul de Minas & $1.773 .100,00$ & 10,00 & 1,71 & 2,30 & 0,74 \\
\hline Planalto do Rio Jequitinhonha - Rio Pardo & $5.965 .700,00$ & 8,00 & 1,62 & 2,08 & 0,78 \\
\hline Planalto do São Francisco & $10.064 .700,00$ & 11,00 & 1,65 & 2,40 & 0,69 \\
\hline Planaltos Dissecados do Centro - Sul e do Leste de Minas & $10.674 .400,00$ & 13,00 & 1,33 & 2,56 & 0,52 \\
\hline Quadrilátero Ferrífero & $493.514,00$ & 6,00 & 1,36 & 1,79 & 0,76 \\
\hline Serra da Canastra & $798.429,00$ & 8,00 & 1,52 & 2,08 & 0,73 \\
\hline Serra da Mantiqueira & $1.179 .010,00$ & 8,00 & 1,71 & 2,08 & 0,82 \\
\hline Serra do Espinhaço & $1.502 .180,00$ & 9,00 & 1,33 & 2,20 & 0,61 \\
\hline Zona Rebaixada do Rio Mucuri & $680.813,00$ & 2,00 & 0,08 & 0,69 & 0,12 \\
\hline
\end{tabular}


A Depressão Sanfranciscana caracteriza-se por apresentar pedodiversidade muito alta. A Zona Rebaixada do Rio Mucuri associa-se o menor valor encontrado. O Planalto Dissecado do Sul de Minas, Serra da Mantiqueira, Planalto do São Francisco, Depressão do Rio Grande, Planalto do Rio Jequitinhonha - Rio Pardo, Depressão do Rio Doce e a Serra da Canastra apresentam alta pedodiversidade. O Quadrilátero Ferrífero, Serra do Espinhaço, Planaltos Dissecados do Centro - Sul e do Leste de Minas e a Depressão do Rio Jequitinhonha apresentam média pedodiversidade. A Depressão do Rio Paraíba do Sul, Depressão do Rio Paranaíba, Depressão Periférica Paulista, Cristas de Unaí e o Planalto da Bacia do Paraná apresentam baixa pedodiversidade. A Zona Rebaixada do Rio Mucuri apresenta o menor valor de pedodiversidade, classificado como muito baixa (Figura 3).
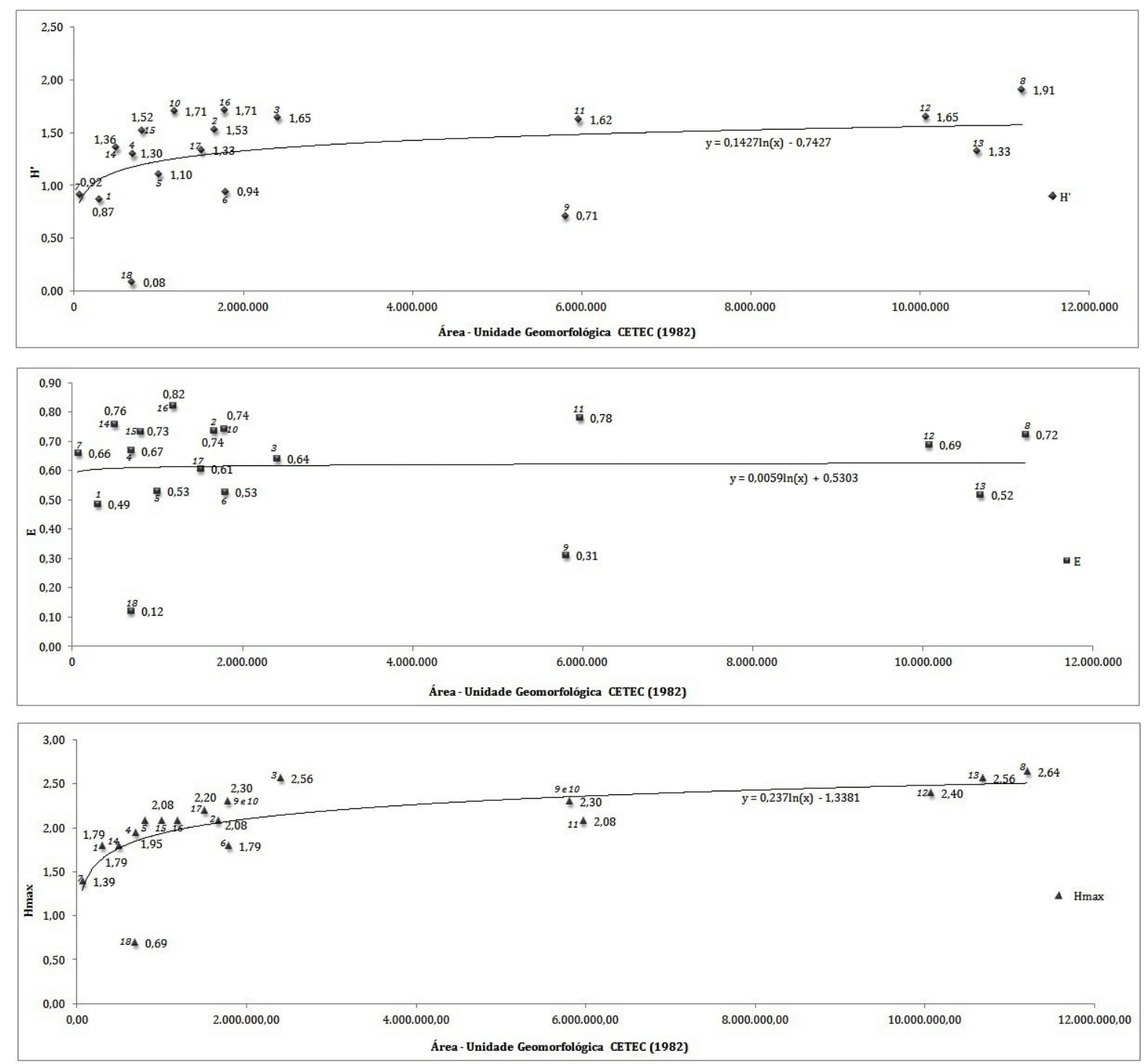

Figura 3 - Índices de pedodiversidade por unidades geomorfológicas em Minas Gerais. (1) Cristas de Unaí; (2) Depressão do Rio Doce; (3) Depressão do Rio Grande; (4) Depressão do Rio Jequitinhonha; (5) Depressão do Rio Paranaíba; (6) Depressão do Rio Paraíba do Sul; (7) Depressão Periférica Paulista; (8) Depressão Sanfranciscana; (9) Planalto da Bacia do Paraná; (10) Planalto Dissecado do Sul de Minas; (11) Planalto do Rio Jequitinhonha - Rio Pardo; (12) Planalto do São Francisco; (13) Planaltos Dissecados do Centro - Sul e do Leste de Minas; (14) Quadrilátero Ferrífero; (15) Serra da Canastra; (16) Serra da Mantiqueira; (17) Serra do Espinhaço; (18) Zona Rebaixada do Rio Mucuri. 
O índice de pedodiversidade $\mathrm{H}^{\prime}$ indica, em uma primeira análise, uma relação direta com a área ocupada pela unidade geomorfológica, de forma que quanto maior a área, maior o valor da pedodiversidade. Porém, sabe -se que o sistema solo é o resultado da interação de fatores complexos e dinâmicos, de forma que a distribuição e variedade das classes de solo em um determinado local ou região apresenta causas outras que não somente a área dessas.

A depressão Sanfranciscana engloba a calha do São Francisco e alguns de seus afluentes. Trata-se, portanto, de um conjunto de depressões, as quais juntamente com as unidades planálticas circundantes (Fig. 4), compõem uma paisagem epigênica. O processo de abertura da depressão Sanfranciscana ocorreu a partir da dissecação de uma paleosuperfície. Trata-se uma extensa superfície de aplanamento, que durante o Cretáceo Superior ocupava vasta extensão no Brasil Oriental, estendendo-se até o Alto Paranaíba. O elevado grau de laterização das coberturas superficiais inseridas nessa unidade geomorfológica sugere condições de estabilidade tectônica durante um longo período temporal, as quais foram interrompidas no Neógeno, precisamente no Mioceno Médio. Nessa época geológica, importantes modificações do nível de base regional iniciaram o desmonte da paisagem esculpida ao longo do Mesozóico. A partir daí, instalam-se os processos relacionados à abertura da depressão Sanfranciscana (VALADÃO, 1998).

A abertura das depressões que compõem a denominada depressão Sanfranciscana está associada à intensificação dos processos fluviais, os quais, por sua vez, passaram a apresentar forte controle neotectônico ao longo do Mioceno. Ou seja, o processo de dissecação do relevo e a consequente abertura das depressões está associada aos sistemas fluviais, sejam eles o do Rio Pardo Pequeno, Rio Jequitaí, por exemplo, ou ao Rio São Francisco propriamente dito, o qual configura o nível de base regional. Neste sentido, ocorrem processos de erosão remontante nos rios de diferentes ordens, condicionando a evolução das cabeceiras. Além do backwearing ligado à erosão remontante, ocorre também o aprofundamento do canal, configurando o downwearing. Rochas mais resistentes à erosão e ao intemperismo passaram a constituir as superfícies mais elevadas, como a Serra do Cabral e a Serra do Espinhaço. Já as rochas com menor resistência ao intemperismo e à erosão, pertencentes ao Supergrupo São Francisco, foram mais intensamente dissecadas, constituindo a depressão propriamente dita. Estes processos de incisão vertical da rede de drenagem acompanhada por erosão remontante ocorreram em múltiplas escalas espaciais, associados aos cursos d'água de variadas ordens de Strahler. O resultado foi a configuração das diversas depressões que compõem a grande unidade denominada depressão Sanfranciscana (VALADÃO, 1998).

Trata-se, portanto, de uma unidade geomorfológica cuja história relacionada à relativa estabilidade tectônica de uma área cratônica; à existência de rochas tenras que favoreceram à atuação do intemperismo e pedogênese; e às especificidades e variedade dos processos pedogenéticos na escala local - considerando a ideia de que a Depressão Sanfranciscana é formada por um conjunto de 
diversas depressões - associados originaram uma área com a maior pedodiversidade do estado de Minas Gerais.

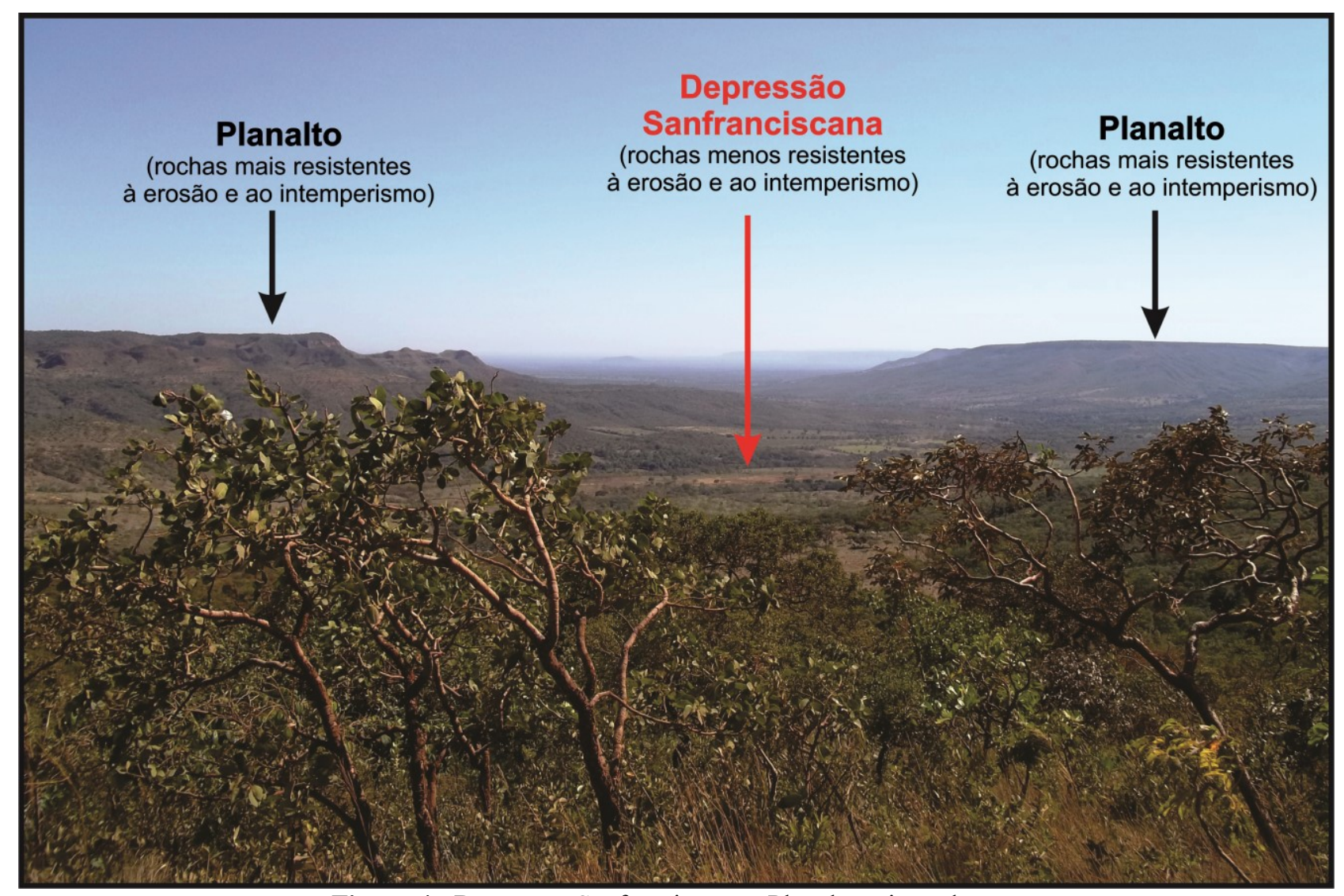

Figura 4 - Depressão Sanfranciscana e Planaltos circundantes.

Fonte - arquivo pessoal dos autores.

\subsection{Análise Conjunta Biomas - Unidades Geomorfológicas e a Identificação de Áreas com Máxima e Mínima Pedodiversidade no estado de Minas Gerais}

Uma análise integrada para os valores de pedodiversidade (H' ou índice de Shannon) obtidos para os biomas e as unidades geomorfológicas permite identificar no território mineiro áreas de máxima ou mínima pedodiversidade, a partir de uma visão que considera elementos climáticos, vegetação e unidades geomorfológicas. Nesse mapa síntese do estado de Minas Gerais fica evidente que a região com a maior pedodiversidade encontra-se na porção da depressão Sanfranciscana inserida no contexto ambiental do bioma cerrado (Fig. 5).

Uma maior pedodiversidade na depressão sanfranciscana associada ao cerrado reforça a importância desse bioma como um hotspot da biodiversidade, caracterizado por uma complexa estrutura fitofisionômica ligada ao contexto de um ecótono localizado na porção central do Brasil. Considerando os resultados desse trabalho, destaca-se que o cerrado no contexto da depressão sanfranciscana constitui um importante hotspot pedológico. Não se trata aqui de minorar a importância das áreas com relativa homogeneidade espacial no que se refere à ocorrência dos solos, mas sim de destacar padrões espaciais específicos. 


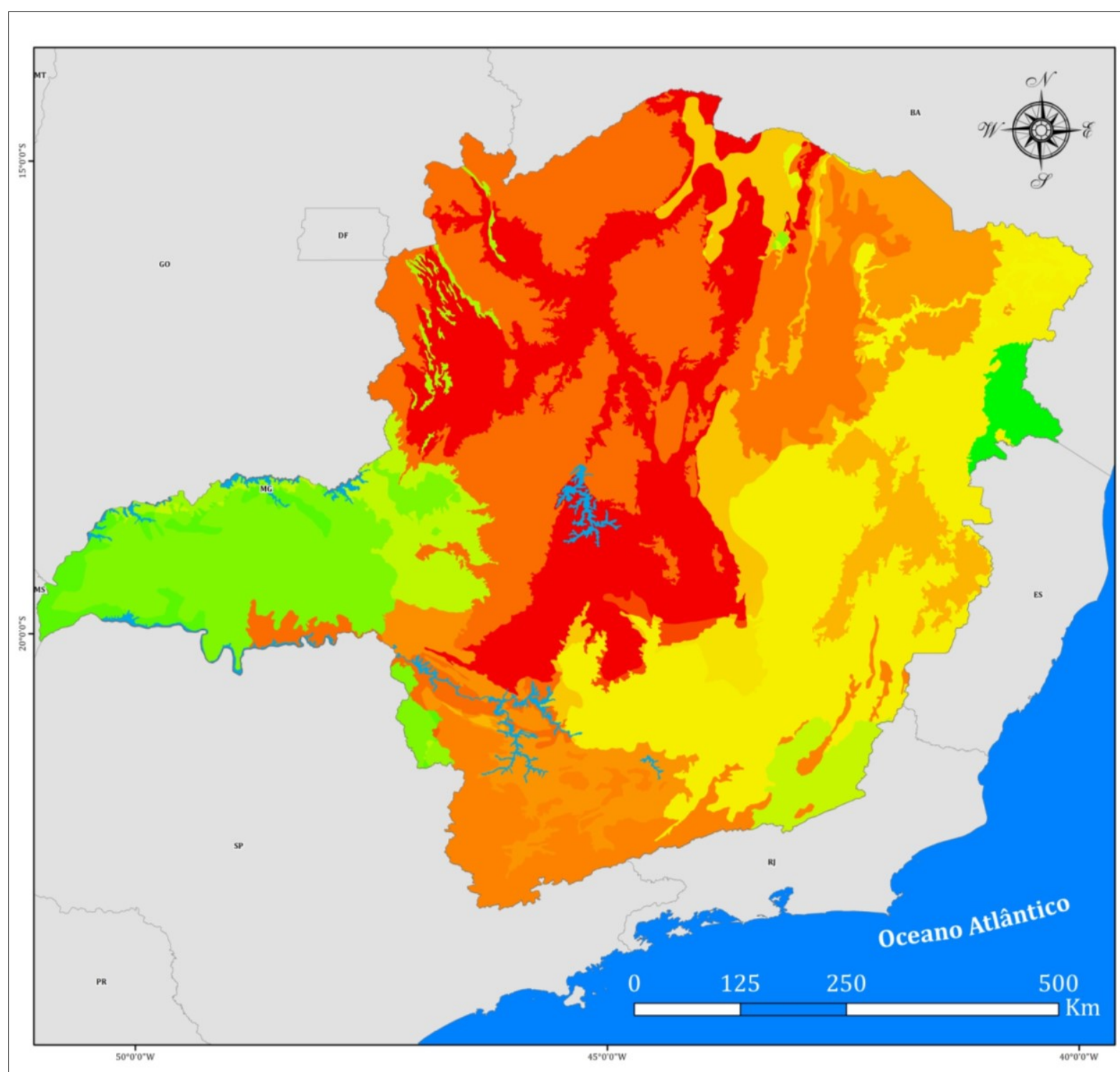

Pedodiversidade

(baseada no índice de Shannon)

Alta

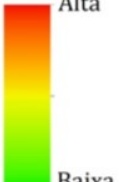

Figura 5 - Pedodiversidade no estado de Minas Gerais. 


\section{CONCLUSÕES}

Inúmeras são as possibilidades de se avaliar a pedodiversidade em diferentes unidades geográficas. A abordagem apresentada nesse trabalho buscou contribuir com o estado da arte do conhecimento pedológico de Minas Gerais, a partir de uma avaliação espacial de natureza taxonômica das classes presentes no estado. A análise dos padrões espaciais com maior ou menor pedodiversidade conduz e reforça uma lógica de áreas com uma maior complexidade de fatores ambientais extrínsecos e intrínsecos. A variabilidade espacial dos solos no território mineiro resulta de um somatório de elementos climáticos, geológicos, geomorfológicos e biológicos cujas possibilidades de interpretação permitem não apenas melhor planejar o uso e ocupação no território, mas também compreender parte da história natural do estado. A partir dos resultados desse trabalho, por exemplo, foi possível apontar a depressão sanfranciscana, especificamente no contexto do bioma cerrado, como um importante hotspot pedológico. Reitera-se, portanto, a importância de se preservar não somente os elementos bióticos da paisagem, mas também os elementos físicos que constituem o substrato para todos os organismos vivos, incluindo os diversos grupos humanos que compõem as ricas paisagens mineiras.

\section{REFERÊNCIAS}

A. S.; AlVAREZ VEnEGAS, V. H. (Ed.). Tópicos em ciência do solo. Volume 3. Viçosa: Sociedade Brasileira de Ciência do Solo, 2003. cap. 3, p.107-164.

AB'SÁBER, A. Os Domínios de Natureza no Brasil: potencialidades paisagísticas. 3. ed. São Paulo: Ateliê, 2003. 159p.

ALYABINA, I. O. Cartographic Assessment of Soil Diversity in Russia. Moscow University Soil Science Bulletin, Moscow, v. 73, n. 1, p. 5-10, 2018.

ARRUDA, M. A.; AMORIM FILHO, O. B. Minas Gerais do Século XXI: reinterpretando o espaço mineiro. Belo Horizonte: Banco de Desenvolvimento de Minas Gerais - BDMG, 2002. 336p.

BOCKHEIM, J. G.; GENNADIYEV, A. N.; HAMMER, R. D.; TANDARICH, J. P. Historical development of key concepts in pedology. Geoderma, Amsterdam, v. 124, n. 1, p. 23-36, 2005.

CASTRO, S. S.; COOPER, M.; SANTOS, M. C.; VIDAL TORRADO, P. Micromorfologia do solo: bases e aplicações. In: CURI, N.; MARQUES, J. J.; GUILHERME, L. R. G.; LIMA, J. M.; LOPES,

CHESWORD, W. Encyclopedia of Soil Science. 2. ed. Dordrecht, Berlin, Heidelberg, New York: Springer Science \& Business Media. 2008. 902p.

FEAM - UFV - CETEC - UFLA. Mapa de solos do Estado de Minas Gerais. Belo Horizonte, Fundação Estadual do Meio Ambiente, 2010. 49p. Escala 1:650.000. Disponível em: $<$ http://www.feam.br/noticias/1/949-mapas-de-solo-do-estado-de-minas-gerais $>$ Acesso em: 12 ago. 2015. 
FUNDAÇÃO CENTRO TECNOLÓGICO DE MINAS GERAIS - CETEC. Projeto Diagnóstico Ambiental - Mapa 2. Geomorfologia. Belo Horizonte. 1982. Escala 1: 1.000.000.

GUO, Y.; GONG, P.; AMUNDSON, R. Pedodiversity in the United States of America. Geoderma, Amsterdam, v. 117, n. 1, p. 99-115, 2003.

HOLE, F. D. An approach to landscape analysis with emphasis on soils. Geoderma, Amsterdam, v. 21, n. 1, p. 1-23, 1978.

HUDSON, B. D. The soil survey as paradigm-based science. Soil Science Society of America Journal, Madison, v. 56, n. 3, p. 836-841, 1992.

IBÁÑEZ, J. J.; BOCKHEIM, J. G. (Eds.). Pedodiversity. 1. ed. Boca Raton: CRC Press, 2013. 244 p.

IBAÑEZ, J. J.; DE-ALBA, S.; BERMÚDEZ, F. F.; GARCÍA-ÁlVAREZ, A. Pedodiversity: concepts and measures. Catena, Amsterdam, v. 24, n. 3, p. 215-232, 1995.

IBAÑEZ, J. J.; DE-ALBA, S.; LOBO, A.; ZUCARELLO, V. Pedodiversity and global soil patterns at coarse scales (with discussion). Geoderma, Amsterdam, v. 83, n. 3, p. 171-192, 1998.

INSTITUTO BRASILEIRO DE GEOGRAFIA E ESTATÍSTICA (IBGE). Mapa de biomas do Brasil. Escala 1:5.000.000. Rio de Janeiro: IBGE, 2004. Disponível em: http://mapas.ibge.gov.br/biomas2/ viewer.htm. Acessado em: 2 jun. 2015.

INSTITUTO BRASILEIRO DE GEOGRAFIA E ESTATÍSTICA (IBGE). Estados@. Disponível em: $<$ http://www.ibge.gov.br/estadosat/perfil.php?sigla=mg $>$. Acessado em: 15 jun. 2015.

JENNY, H. Factors of soil formation. 1. ed. New York: Macraw-Hill, 1941. 285p.

KOOISTRA, M. J. The Future of Soil Micromorphology. In: DOUGLAS, L. A. Soil Micromorphology: a Basic and Applied Science. Amsterdam: Elsevier, 1990. Preface. p. 1-7.

MAZZETTO SILVA, C. E. Ordenamento Territorial no Cerrado brasileiro: da fronteira monocultora a modelos baseados na sociobiodiversidade. Desenvolvimento e Meio Ambiente, Curitiba, v. 19, p. 89-109, jan/jun. 2009.

MCBRATNEY, A.; MINASNY, B. On measuring pedodiversity. Geoderma, Amsterdam, v. 141, n. 1, p. 149-154, 2007.

MILLER, B. A.; SCHAETZL, R. J. History of soil geography in the context of scale. Geoderma, Amsterdam, v. 264, p. 284-300, 2016.

PHILLIPS, J. D. Divergent evolution and the spatial structure of soil landscape variability. Catena, Amsterdam, v. 43, n. 2, p. 101-113, 2001a.

PHILLIPS, J. D. The relative importance of intrinsic and extrinsic factors in pedodiversity. Annals of the Association of American Geographers, Washington, v. 91, n. 4, p. 609-621. 2001 b.

SALDAÑA, A.; IBÁÑEZ, J. J. Pedodiversity, connectance and spatial variability of soil properties, what is the relationship? Ecological Modelling, Amsterdam, v. 208, n. 2, p. 342-352, 2007.

SANTOS, H. G.; JACOMINE, P. K. T.; ANJOS, L. H. C.; OLIVEIRA, V. A.; LUMBRERAS, J. F.; COELHO, M. R.; ALMEIDA, J. A.; ARAUJO FILHO, J. C.; OLIVEIRA, J. B.; CUNHA, T. J. 
F. Sistema Brasileiro de Classificação de Solos. 5. ed. Brasília: Embrapa, 2018. 187p. Disponível em: https://www.embrapa.br/solos/busca-de-publicacoes/-/publicacao/1094003/sistema-brasileirode-classificacao-de-solos. Acesso em: 18 out. 2018.

SCHAEFER, C. E. G. R. Bases Físicas da Paisagem Brasileira: estrutura geológica, relevo e solos. Tópicos em Ciência do Solo, v. 8, p. 1-69, 2013.

SCHAETZL, R. J.; ANDERSON, S. Soil classification, mapping and maps. In: SCHAETZL, R. J.; ANDERSON, S. Soils: Genesis and Geomorphology. New York: Cambridge University Press, 2005. cap. 7, p. 106-158.

VALADÃO, R. C. Evolução de longo termo do relevo do Brasil Oriental: desnudação, superfícies de aplanamento e soerguimentos crustais. 1998. 243 f. Tese (Doutorado em Geologia Sedimentar) Instituto de Geociências, Universidade Federal da Bahia, Salvador, 1998.

Trabalho enviado em 18/11/2018

Trabalho aceito em 18/12/2018 